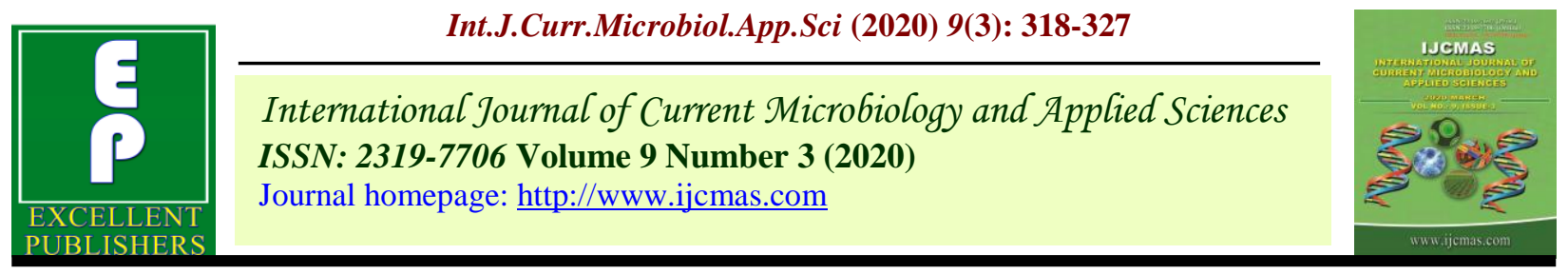

Original Research Article

https://doi.org/10.20546/ijcmas.2020.903.038

\title{
Isolation and Molecular Identification of Riemerella anatipestifer from Ducks in Assam
}

\author{
Ritam Hazarika $^{1 *}$, M. K. Doley ${ }^{2}$, H. Sarmah ${ }^{2}$, P. Deka ${ }^{2}$ and R. K. Sharma ${ }^{2}$ \\ ${ }^{1}$ Department of Animal Biotechnology, ${ }^{2}$ Department of Microbiology, College of Veterinary \\ Science, A.A.U. Khanapara, Guwahati-781022, Assam, India \\ *Corresponding author
}

\begin{tabular}{|c|}
\hline Keywords \\
\hline $\begin{array}{l}\text { Assam, Ducks, } \\
\text { Polymerase Chain } \\
\text { Reaction, } \\
\text { Riemerella } \\
\text { anatipestifer }\end{array}$ \\
\hline Article Info \\
\hline $\begin{array}{l}\text { Accepted: } \\
\text { 05 February } 2020 \\
\text { Available Online: } \\
10 \text { March } 2020\end{array}$ \\
\hline
\end{tabular}

\section{A B S T R A C T}

Considering the highest duck population in the eastern part of India, a preliminary study was carried out in Assam to investigate duck septicaemia like disease condition and the association of Riemerella anatipestifer in ducks. Among the 98samples collected from ducks (34) comprising healthy ducks (10), ducks with clinical symptoms (19), suggestive of duck septicaemia and dead ducks (5); 13 samples revealed isolation of $R$. anatipestifer. Molecular confirmation of the isolates, using $R$. anatipestifer specific PCR assay (564 bp), as well as gyrB-based PCR (162 bp) revealed both the genes to be suitable molecular markers for identification of the isolates as $R$. anatipestifer. Kirby-Bauer disc diffusion tests were used to analyze the antibiotic resistance of $13 R$. anatipestifer isolates. The present study is the first report of molecular detection of $R$. anatipestifer from ducks in Guwahati, Assam and suggests that the PCR assay can facilitate fast and accurate identification of $R$. anatipestifer infection in ducks during disease outbreaks.

\section{Introduction}

Among the states of India, Assam is considered to be the second-highest duck populated (7.21 million) state. Despite the natural resistance, ducks may be affected by many diseases prevalent in poultry. Out of the bacterial diseases, New Duck disease or duck septicaemia caused by Riemerella anatipestifer, a gram-negative, non-motile, nonspore-forming, rod-shaped bacterium, is considered to be an economically important disease throughout the world, resulting in high morbidity and mortality rates in ducks. It was reported and described by Riemer, for the first time in 1904 (Segers et al., 1993). Kardos et al., (2007) developed a novel PCR assay proved to be specific for R. anatipestifer and capable of correctly identifying it from pure cultures as well as 
clinical samples from birds. In a recent study, Udayan et al., (2019) reported the universal gyrase B-encoding gene $($ gyr $\mathrm{B})$, a type II DNA topoisomerase as a more accurate, sensitive and specific marker for $R$. anatipestifer identification. $R$. anatipestifer infection can be treated and controlled by judicious use of suitable antibiotics. Therefore, the antibiotic sensitivity test is a must to ensure maximum drug effectiveness by minimizing the needless use of antibiotics to which $R$. anatipestifer is resistant.

\section{Materials and Methods}

\section{Sample collection}

During the months of March to June 2019, heavy mortality in ducklings (4-8 weeks of age) was recorded from Guwahati, Assam and its surrounding areas (Fig. 1) with notable signs of respiratory distress and neurological signs, such as trembling of head and neck, paddling of legs and ataxia (Fig. 2). None of the ailing and dead ducks, subjected to the Dept. of Microbiology, College of Veterinary Science, Khanapara, Guwahati (Assam) could reveal duck plague infection, confirmed by PCR based detection of duck plague specific DNA directed DNA polymerase (UL-30) gene. For the bacteriological investigation, a total of 98 nos. of clinical samples, comprising of ocular and pharyngeal swabs, liver, lungs, kidney, brain, spleen and heart blood were collected from apparently healthy ducks (10), clinically affected ducks (19) and dead ducks (5) (Table 1). Samples were collected aseptically and immediately processed for bacteriological examination.

\section{Isolation and identification}

Collected samples were processed for isolation of Riemerella anatipestifer by inoculating into $10 \mathrm{ml}$ of Brain Heart Infusion (BHI) broth (Hi-media) with overnight incubation at $37^{\circ} \mathrm{C}$ under a micro-aerophilic condition in a candle jar. Blood agar (BA) plates were inoculated with inoculum from overnight $\mathrm{BHI}$ broth culture and further incubated for $24 \mathrm{hrs}$ in micro-aerophilic condition at $37^{\circ} \mathrm{C}$ inside a candle jar. Based on colony morphology and staining reaction, exhibiting characteristic Gram-negative bipolar short rods were tentatively identified as $R$. anatipestifer and were considered for molecular confirmation.

\section{Molecular confirmation of $\boldsymbol{R}$. anatipestifer}

All the morphologically identified $R$. anatipestifer isolates were considered for molecular confirmation by Polymerase Chain Reaction (PCR). Template DNA was prepared from each tentatively identified $R$. anatipestifer isolates by hot cold lysis method (Titball et al., 1989) and assessed for molecular confirmation by $R$. anatipestifer species-specific PCR (546 bp) and gyrBgene (162 bp) based PCR.

\section{Riemerella anatipestifer species-specific PCR}

DNA extracted from all the tentatively identified field isolates were singly determined for Riemerella anatipestifer by species-specific PCR assay (Kardos et al., 2007), with the primer sequence mentioned in Table 2. Simplex PCR was carried out with reaction mixture, comprising of $3.0 \mu \mathrm{l}$ (100$150 \mathrm{ng})$ of respective template DNA, $12.5 \mu \mathrm{l}$ of $2 \mathrm{X}$ Dream Taq master mixture (Fermentas), $0.7 \mu \mathrm{l}$ (10 pmol conc.) of each forward and reverse primers and sufficient Nuclease-Free Water (NFW) to make the final vol. of $25.0 \mu 1$. One additional negative control without template DNA was included to monitor any contamination.

PCR was carried out in thermocycler (Techne, USA) with cycling conditions, mentioned by 
Sarker et al., (2017) with slight modification (Table 3). The amplified PCR products were electrophoresed in $1.5 \%$ agarose gel stained with ethidium bromide for $1 \mathrm{hr}$ at $50 \mathrm{~V}$ and were visualized by UV light in the gel documentation system (DNR Bioimaging System Minilumi, Sigma). The amplified DNA was sequenced from Eurofins Genomics India Pvt. Ltd. Bengaluru, Karnataka, India and sequence result was validated by performing a sequence alignment with $R$. anatipestifer specific gene sequences in GenBank, using genetic analysis software.

\section{Molecular Detection of $\operatorname{gyr} B$ gene}

Extracted DNA of respective $R$. anatipestifer isolates were further tested for the presence of a gyrBgene (162 bp) by simplex PCR, as mentioned by Udayan et al., (2019) with slight modifications. Details of primers sequences for the gyr $B$ gene are tabulated in Table 1. The composition used in $25.0 \mu \mathrm{l}$ reaction mixture was the same as that of Riemerella anatipestifer species-specific PCR assay except for an additional $0.5 \mu \mathrm{l}$ of $\mathrm{MgCl}_{2}$ $(25 \mathrm{mM})$. PCR programme for amplification of the $g y r \mathrm{~B}$ gene was done with reported thermocycling condition as shown in Table 3.

\section{Antimicrobial Resistance pattern of Riemerella anatipestifer isolates}

Riemerella anatipestifer isolates recovered during the study were characterized in respect to their resistance pattern towards few commonly used antimicrobials (HiMedia Lab, Mumbai), viz., ciprofloxacin (5 mcg/disc), enrofloxacin (10 mcg/disc), ofloxacin (5 $\mathrm{mcg} / \mathrm{disc})$, streptomycin $(10 \mathrm{mcg} / \mathrm{disc})$, neomycin (30 mcg/disc), lincomycin (15 $\mathrm{mcg} / \mathrm{disc})$, gentamicin (30 mcg/disc) and cefazolin $(30 \mathrm{mcg} / \mathrm{disc})$ by Kirby-Bauer disk diffusion susceptibility test (Bauer et al.,1966).

\section{Results and Discussion}

Bacteriological examination of98 clinical samples revealed 41 samples to be bacteriologically positive, yielding an equal no. of isolates under micro-aerophilic environment. Isolates with a typical nonhaemolytic colony, gram-negative and bipolar staining reaction and non-motile short rods were tentatively identified as $R$. anatipestifer. Similar cultural, morphological and staining characteristics were also reported by Surya $e t$ al., (2016). However, they also recorded one isolate to be haemolytic.

\section{Riemerella anatipestifer species-specific PCR assay}

Screening of all 41 morphologically identified isolates for PCR based identification could confirm 13 isolates to be $R$. anatipestifer. All confirmed isolates were found to exhibit the desired amplicon size of 546 bp for $R$. anatipestifer species-specific PCR assay (Fig.3). Majority of the $R$. anatipestifer isolates were recovered from ocular swabs (6) and pharyngeal (5) of clinically infected ducks, while only two isolates from infected liver of dead ducks were confirmed to be $R$. anatipestifer positive. However, $R$. anatipestifer species-specific PCR assay could not reveal the presence of $R$. anatipestifer in any of the suspected isolates from lungs, kidneys, spleen, brain and heart blood of clinically infected ducks. Amplified product with band size $546 \mathrm{bp}$, suggestive of $R$. anatipestifer species-specific gene was confirmed by sequencing and validating with the NCBI website (Table 3). PCR based identification affirmed all the samples of apparently healthy ducks to be negative for $R$. anatipestifer.

Considering the sporadic duck population in India, a very little in-depth study could be traced out from available literature in respect 
to the duck disease of bacterial origin. An $R$. anatipestifer like infection in the duck population, as reported by Sarma et al., (1985) may be considered to be the earliest report from Assam, India. Similarly, Shome et al., (2004) observed an outbreak in ducks of Meghalaya, India. However, they identified the outbreak of the infections, based on clinical manifestation and pathological alteration at necropsy. Priya et al., (2008) could also record a similar type of infection from Kerala for the first time in duck. Association of Riemerella anatipestifer with all these previous studies from India were based on conventional isolation, identification and biochemical characterization, which proved to be tedious and problematic in differentiating with Pasteurella multocida.

Table.1 Collection of samples for isolation of Riemerella anatipestifer isolates

\begin{tabular}{|c|c|c|c|c|}
\hline $\begin{array}{l}\text { Nature of } \\
\text { samples }\end{array}$ & $\begin{array}{l}\text { No. of samples } \\
\text { screened for } \\
\text { Riemerella } \\
\text { anatipestifer }\end{array}$ & $\begin{array}{l}\text { No. of isolates } \\
\text { positive for the } \\
\text { Riemerella } \\
\text { anatipestifer specific } \\
\text { gene }\end{array}$ & $\begin{array}{l}\text { No. of isolates } \\
\text { positive for } \\
\text { Riemerella } \\
\text { anatipestifer specific } \\
\text { gyrB gene }\end{array}$ & $\begin{array}{l}\text { Samples } \\
\text { confirmed } \\
\text { for } \\
\text { Riemerella } \\
\text { anatipestifer }\end{array}$ \\
\hline \multicolumn{5}{|c|}{ 1. Apparently Healthy Birds (10) } \\
\hline $\begin{array}{l}\text { Ocular } \\
\text { Swabs }\end{array}$ & 10 & 0 & 0 & 0 \\
\hline $\begin{array}{l}\text { Pharyngeal } \\
\text { Swabs }\end{array}$ & 10 & 0 & 0 & 0 \\
\hline Total & 20 & 0 & 0 & 0 \\
\hline \multicolumn{5}{|c|}{ 2. Clinically Affected Birds(19) } \\
\hline $\begin{array}{l}\text { Ocular } \\
\text { Swabs }\end{array}$ & 19 & 6 & 6 & 6 \\
\hline $\begin{array}{l}\text { Pharyngeal } \\
\text { Swabs }\end{array}$ & 19 & 5 & 5 & 5 \\
\hline Total & 38 & 11 & 11 & 11 \\
\hline \multicolumn{5}{|c|}{ 3. Dead Birds(5) } \\
\hline $\begin{array}{l}\text { Ocular } \\
\text { Swabs }\end{array}$ & 5 & 0 & 0 & 0 \\
\hline $\begin{array}{l}\text { Pharyngeal } \\
\text { Swabs }\end{array}$ & 5 & 0 & 0 & 0 \\
\hline Liver & 5 & 2 & 2 & 2 \\
\hline Lungs & 5 & 0 & 0 & 0 \\
\hline Kidney & 5 & 0 & 0 & 0 \\
\hline Spleen & 5 & 0 & 0 & 0 \\
\hline Brain & 5 & 0 & 0 & 0 \\
\hline $\begin{array}{l}\text { Heart } \\
\text { blood }\end{array}$ & 5 & 0 & 0 & 0 \\
\hline Total & 40 & 2 & 2 & 2 \\
\hline $\begin{array}{l}\text { Grand } \\
\text { total }\end{array}$ & 98 & 13 & 13 & $13(13.3 \%)$ \\
\hline
\end{tabular}


Table.2 Primers used to characterize the Riemerella anatipestifer isolates

\begin{tabular}{|c|c|c|c|c|}
\hline Primer & Sequence $\left(5^{\prime}-33^{\prime}\right)$ & Target & $\begin{array}{c}\text { Produc } \\
t \\
\operatorname{size}(b p)\end{array}$ & Reference \\
\hline $\begin{array}{l}\text { Riemerella } \\
\text { anatipestifer-F }\end{array}$ & TTACCGACTGATTGCCTTCTA & \multirow{2}{*}{$\begin{array}{l}\text { Riemerella } \\
\text { anatipestifers } \\
\text { pecies- } \\
\text { specific gene }\end{array}$} & \multirow[t]{2}{*}{546} & \multirow[t]{2}{*}{$\begin{array}{l}\text { Kardos et } \\
\text { al., (2007) }\end{array}$} \\
\hline $\begin{array}{l}\text { Riemerella } \\
\text { anatipestifer-R }\end{array}$ & AGAGGAAGACCGAGGACATC & & & \\
\hline gyrB-F & GGCTAAGGCAAGACAAGCTG & \multirow[t]{2}{*}{ gyrB gene } & \multirow[t]{2}{*}{162} & \multirow{2}{*}{$\begin{array}{l}\text { Udayan et } \\
\text { al., (2019) }\end{array}$} \\
\hline gyrB-R & GCAGTTCCTCCTGCAGAGTC & & & \\
\hline
\end{tabular}

Table.3 Thermocycling conditions for molecular detection of Riemerella anatipestifer speciesspecific and gyrB genes

\begin{tabular}{|c|c|c|c|c|}
\hline Target gene & Conditions & Temperature & Duration & $\begin{array}{l}\text { No. of } \\
\text { Cycles }\end{array}$ \\
\hline \multirow{5}{*}{$\begin{array}{c}\text { Riemerella } \\
\text { anatipestifer species- } \\
\text { specific gene } \\
\text { (Sarker } \text { et al., 2017) }\end{array}$} & Initial Denaturation & $95^{\circ} \mathrm{C}$ & 5 & \\
\hline & Denaturation & $94^{\circ} \mathrm{C}$ & 1 & \multirow[t]{3}{*}{44} \\
\hline & Prime Annealing & $61^{\circ} \mathrm{C}$ & 3 & \\
\hline & Extension & $72^{\circ} \mathrm{C}$ & 2 & \\
\hline & Final Extension & $72^{\circ} \mathrm{C}$ & 7 & \\
\hline \multirow{5}{*}{$\begin{array}{c}\text { gyrB gene } \\
\text { (Udayan et al., } \\
\text { 2019) }\end{array}$} & Initial Denaturation & $95^{\circ} \mathrm{C}$ & 4 & \multirow{4}{*}{35} \\
\hline & Denaturation & $95^{\circ} \mathrm{C}$ & 1 & \\
\hline & Primer Annealing & $55^{\circ} \mathrm{C}$ & 1 & \\
\hline & Extension & $72^{\circ} \mathrm{C}$ & 1 & \\
\hline & Final Extension & $72^{\circ} \mathrm{C}$ & 7 & \\
\hline
\end{tabular}

Table.4 Detail of BLAST output for the sequenced PCR products

\begin{tabular}{|l|l|l|l|l|}
\hline \multicolumn{1}{|c|}{ Target gene } & \multicolumn{1}{|c|}{ Description of the top result } & $\begin{array}{c}\text { Gen Bank } \\
\text { accession }\end{array}$ & $\begin{array}{c}\text { Max } \\
\text { identity } \\
(\%)\end{array}$ & $\begin{array}{c}\text { E- } \\
\text { value }\end{array}$ \\
\hline $\begin{array}{l}\text { R.anatipestifer specific } \\
\text { gene } \\
\text { (Riemerella anatipestifer } \\
\text { strain D-26220 RNAse Z } \\
\text { and xanthosine } \\
\text { triphosphatepyrophosphat } \\
\text { ase genes, partial cds). }\end{array}$ & $\begin{array}{l}\text { Riemerella anatipestifer strain D- } \\
\text { 26220 RNAse Z and xanthosine } \\
\text { triphosphate pyrophosphatase } \\
\text { genes, partial cds. }\end{array}$ & JN578235.1 & 96.74 & 0 \\
\hline
\end{tabular}


Figure.1 Geographic origin of the samples collected for this study

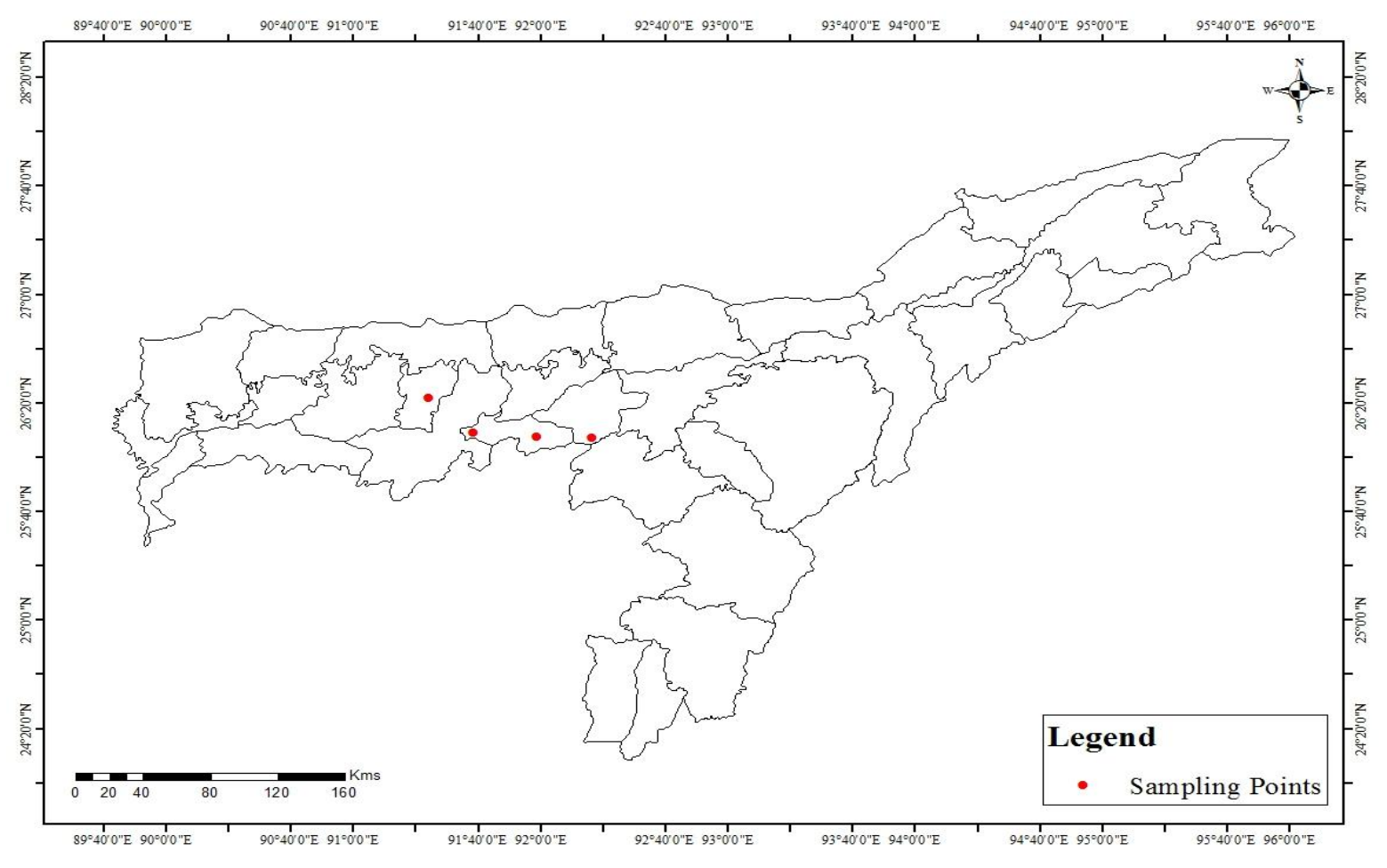

Figure.2 Clinically affected ducks

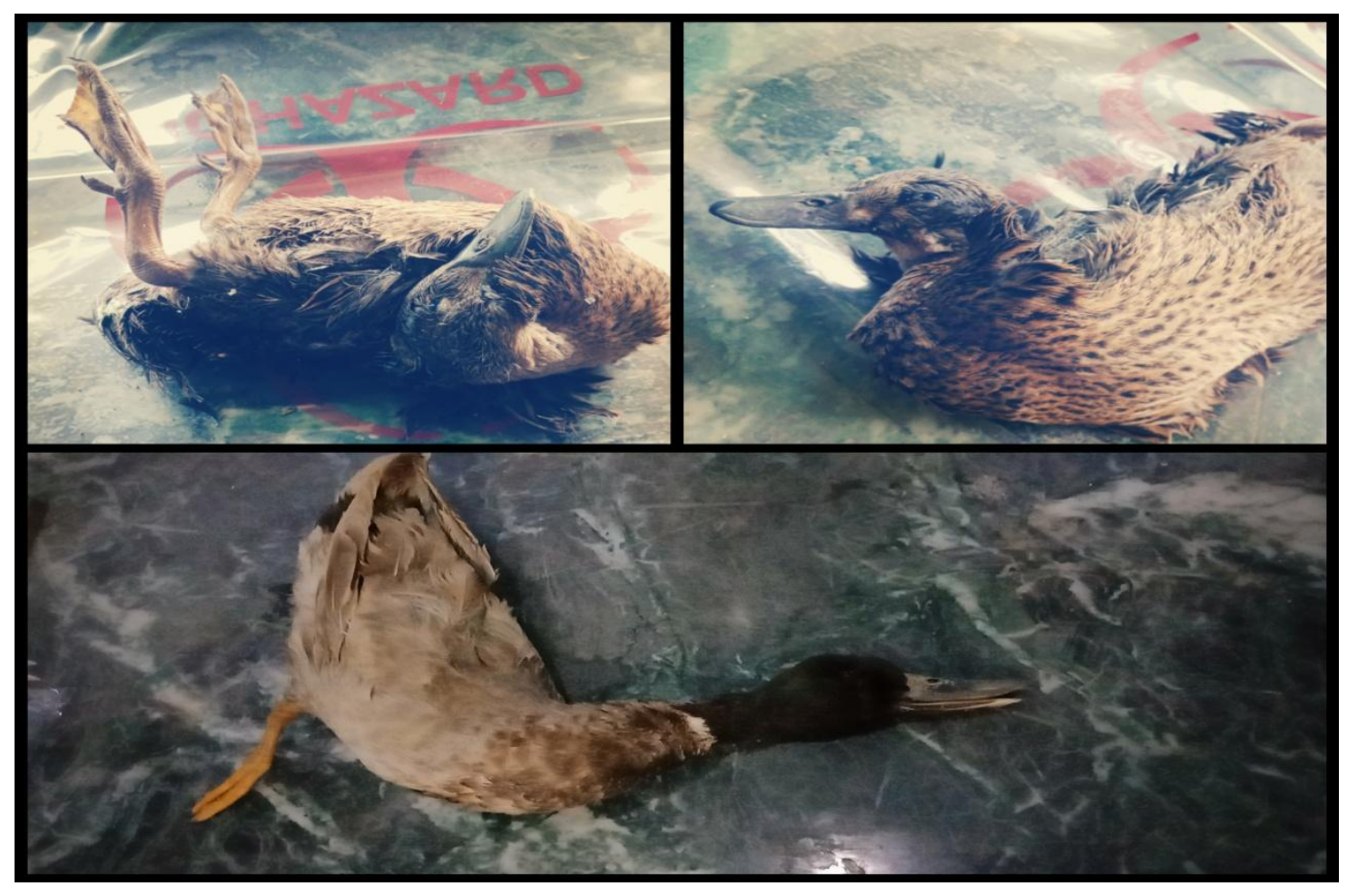


Figure.3 Detection of Riemerella anatipestifer species-specific PCR assay in the field isolates

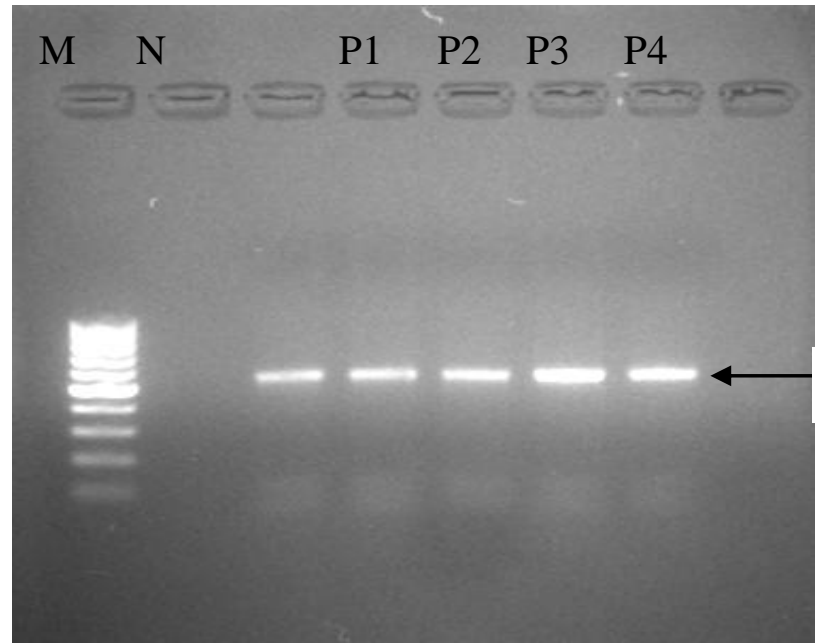

$546 \mathrm{bp}$

$\mathrm{M}=$ Marker, Lane $\mathrm{N}=$ Negative control, Lane $\mathrm{P}$ to $\mathrm{P} 4=$ field isolates positive for $R$. anatipestiferspecies-specific gene (546 bp).

Figure.4 Detection of Riemerella anatipestifer specific gyrB gene in the field isolates by PCR

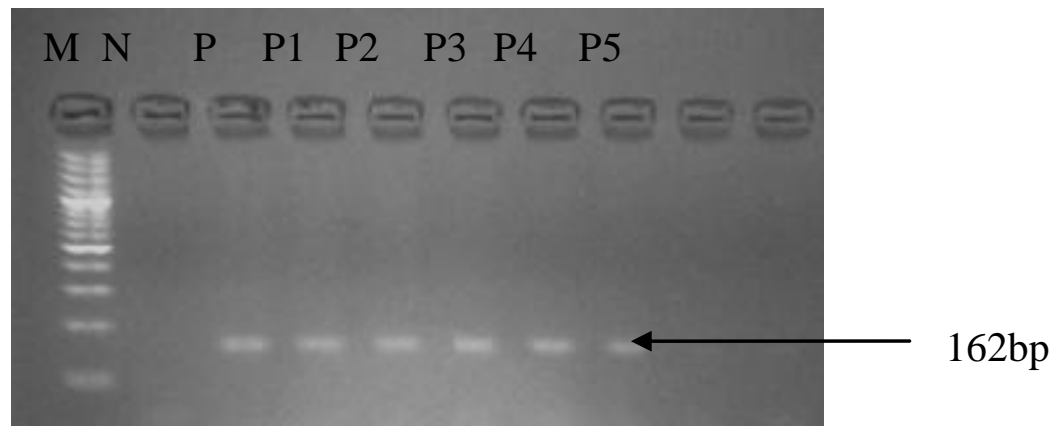

$\mathrm{M}=$ Marker, Lane $\mathrm{N}=$ Negative control, Lane $\mathrm{P}$ to $\mathrm{P} 5=$ field isolates positive for $R$. anatipestifer species-specific gene (162 bp).

Considering the phenotypic similarity with $P$. multocida and importance of $R$. anatipestifer infection, Kardos et al., (2007) successfully presented a suitable molecular-based method with designed primers for proper identification of $R$. anatipestifer from cultures. They recorded 546 bp PCR amplicon size in all the 72 clinical isolates of $R$. anatipestifer. Contrary to present observation, Sarker et al., (2017) could confirm 37 out of 60 suspected $R$. anatipestifer isolates, based on visible $421 \mathrm{bp}$ fragment of ribonuclease $\mathrm{Z}$ gene, using the same primer sequence of Kardos et al., (2007) for 546 bp size gene. In support of the $421 \mathrm{bp}$ amplicon size, instead of $546 \mathrm{bp}$, they opined for a probable mutation in the amino acid sequence of isolates from Bangladesh. Confirmation of two suspected $R$. anatipestifer isolates, based on detection of a species-specific gene with an amplicon size of $546 \mathrm{bp}$ was also reported by Shancy et al., (2018).

\section{Molecular detection of gyrB gene}

Exploring for the universal gyrase B-encoding gene could reveal the presence of the gyrB gene in all the 12 isolates that were found 
positive for $R$. anatipestifer species-specific PCR assay. All the isolates could exhibit a band size of 162bp (Fig.4). Considering the limitation of $16 \mathrm{~S}$ rRNA as molecular marker to differentiate closely related bacteria, because of low mutation rate, the DNA gyrase, subunit B associated gene (gyrB) was identified as an equally good marker sequence for the classification of bacteria at the species and subspecies level (Kumar et al., 2006 and Takeda et al., 2010). In a comparative study, Wang et al., (2012) could confirm gyrB-based PCR to be more consistent and was more specific $(100.0 \%)$ for detection of $R$. anatipestifer strains in comparison to the $16 \mathrm{~S}$ rRNA based PCR (63.6\%). In similar comparison with a pair of PCR primers designed for $g y r \mathrm{~B}$ gene sequence of $R$. anatipestifer, Udayan et al., (2019) concluded the gyrB-based PCR to be more accurate than 16S rRNA sequence-based PCR with confirmation of $R$. anatipestifer in a record $93.3 \%$ of throat swabs. They also opined for a faster evolutionary rate of the gyrB gene as main criteria behind its selection and application.

\section{Antimicrobial Resistance pattern of Riemerella anatipestifer isolates}

Among the 8 different antimicrobial agents used, the isolates were found to be highly sensitive to enrofloxacin, ciprofloxacin, ofloxacin and neomycin; intermediately sensitive to streptomycin and lincomycin, and resistant to gentamicin as well as cefazolin. Upon comparing the results of the present study with that of previous works (Zhong et al., 2009 and Surya et al., 2016) conducted on antibiotic sensitivity of $R$. anatipestifer, the antibiotic sensitivity of $R$. anatipestifer is found to vary with time, thus it is best to perform antibiotic sensitivity test before prescribing and administering the best choice of antibiotic for treatment of $R$. anatipestifer infection in ducks.
In conclusion, the above findings represent the presence of Riemerella anatipestifer in the ducks during a disease outbreak. The present study is the first report of molecularly confirmed isolation of $R$. anatipestifer in ducks of Guwahati, Assam. The pathway of $R$. anatipestifer transmission was not established in this outbreak study. Hence, further studies are necessary to contribute to developing knowledge in $R$. anatipestifer infection from ducks of Assam.

\section{References}

Bauer, A. W., W. M. M. Kirby, J. C. Sherris, and M. Turck. 1966. Antibiotic susceptibility testing by a standardized single disk method. American Journal of Clinical Pathology. 36:493-496.

Kardos, G., Nagy, J., Antal, M., Bistyák, A., Tenk, M. and Kiss, I. 2007. Development of a novel PCR assay specific for Riemerella anatipestifer.Letters in Applied Microbiology. 44:145-148.

Kumar, H.S., Parvathi, A., Karunasagar, I. \&Karunasagar, I. 2006. A gyrB-based PCR detection of Vibrio vulnificus and its application for direct detection of this pathogen in oyster enrichment broths. International Journal of Food Microbiology. 111: 216-220.

Priya, P.M., Pillai, D.S., Balusamy, C., Rameshkumar, P. and Senthamilselvan, P. 2008. Studies on outbreak of new duck disease in Kerala, India. International Journal of Poultry Science. 7: 189-190.

Sarker, R.R., Rahman, M.S., Haque, M.E., Rima, U.K., Hossain, M.Z., et al., 2017. Identification of Ribonuclease $Z$ Gene from an Outbreak of Riemerella anatipestifer Infection in Ducks of Bangladesh. Poultry, Fisheries \& Wildlife Sciences. 5(2): 185.

Sarma, D. K., Baruah. K. K and Boro. B. R. 
1985. Isolation of Pasteurella anatipestifer and $P$. haemolytica from an outbreak of duck mortality. International Journal of Poultry Science. 20:326-327.

Segers, P., Mannheim, W., Vancanneyt, M., De Brandt, K., Hinz, K.H., Kersters, K., et al., 1993. Riemerella anatipestifer gen. nov., comb.nov. the causative agent of septicaemia an serum exudative, and its phylogenetic affiliation within the FlavobacteriumCytophaga rRNA homology group. International Journal of Systematic and Evolutionary Microbiology 43: 768-776.

Shancy, C., Priya, P.M., SabnamV.S., Radhika, S. and Mini, M. 2018. Rapid Detection of Riemerella anatipestifer Isolates using 16srrna based PCR and species-specific PCR assay. International Journal of Science, Environment and Technology, Vol. 7, No 5: 2018, 1802 - 1812.

Shome, R., Shome, B.R, Rahman, H., Murugkar, H.V., Kumar, A., Bhatt, B.P., and Bujarbaruah, K.M. 2004. An outbreak of Riemerella anatipestifer infection in ducks in Meghalaya. Indian Journal of Comparative Microbiology, Immunology and Infectious Diseases, 25: 126-127.

Surya, P.S., Priya, P.M. and Mini, M. 2016. Biotyping and antibiogram of Riemerella anatipestifer from ducks in
Kerala. Bioscience Biotechnology Research Communications. 9 (3): 457462.

Takeda, K., Kang, Y., Yazawa, K., Gonoi, T. and Mikami, Y. 2010. Phylogenetic studies of Nocardia species based on gyrB gene analyses. Journal of Medical Microbiology, 59(2): 165171.

Titball, R.W., Hunter, S.E.C., Martin, K.L., Morris, A.D., Shuttle-worth, A.D., Rubdige, T., Anderson, D.W., Kelly, D.C. 1989. Molecular cloning and nucleotide sequence of the alpha toxin of Clostridium perfringens. Infection and Immunity .57:367-376.

Udayan, P.G., Priya, P.M., Siniya, $\underline{\text { K., Balan, }}$ R. and Mini, M. 2019. Detection of Riemerellosis in Ducks by gyrB GeneBased Polymerase Chain Reaction. International Journal of Livestock Research. 9(1): 238-24.

Wang, X., Zhu, D., Wang, M., Cheng, A., Jia, R., Zhou, Y., Chen, Z., Luo, Q., Liu, F., Wang, Y. and Chen, X. 2012. Complete genome sequence of Riemerella anatipestifer reference strain. Journal of Bacteriology.194: 3270 .

Zhong, C.Y., Cheng, A.C., Wang, M.S., Zhu, D.K., Luo, Q. H., Zhong, C.D., Li, L. and Duan, Z. 2009. Antibiotic susceptibility of Riemerella anatipestifer field isolates. Avian Disease. 2009; 53(4):601-7.

\section{How to cite this article:}

Ritam Hazarika, M. K. Doley, H. Sarmah, P. Deka and Sharma, R. K. 2020. Isolation and Molecular Identification of Riemerella anatipestifer from Ducks in Assam. Int.J.Curr.Microbiol.App.Sci. 9(03): 318-327. doi: https://doi.org/10.20546/ijcmas.2020.903.038 